\title{
ASSITED CONVECTIVE HEAT TRANSFER AND ENTROPY GENERATION IN A SOLAR COLLECTOR FILLED WITH NANOFLUID
}

\author{
R. Nasrin*, a, b, M. A. Alim ${ }^{\text {a }}$, M. Hasanuzzaman ${ }^{\text {b }}$ \\ ${ }^{a}$ Department of Mathematics, Bangladesh University of Engineering and Technology, Dhaka-1000, Bangladesh. \\ E-mail: rehena@math.buet.ac.bd

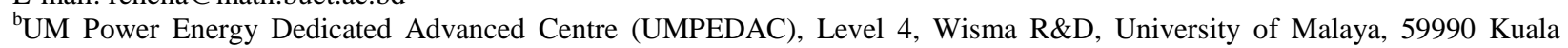 \\ Lumpur, Malaysia. E-mail: hasan@um.edu.my \\ *E-mail: rehena@um.edu.my
}

\begin{abstract}
:
Heat transfer phenomena of flat plate solar collector filled with different nanofluids has been investigated numerically. Galerkin's Finite Element Method is used to solve the problem. Heat transfer rate, average bulk temperature, average sub-domain velocity, outlet temperature, thermal efficiency, mean entropy generation and Bejan number has been investigated by varying the solid nanoparticle volume fraction of water/Cu, water/Ag and water/Cu/Ag nanofluids from $0 \%$ to $3 \%$. It is found that the solid nanoparticle volume fraction has great effect on heat transfer phenomena. It is observed that the increase in the solid volume fraction (up to 2\%) enhances the heat transfer rate and collector efficiency where after $2 \%$ the rate of change almost constant. Higher heat transfer rate and collector efficiency has been obtained $19 \%$ and $13 \%$ for water/Ag nanofluid respectively.
\end{abstract}

Keywords: Assisted convection, flat plate collector, finite element method, nanofluids, entropy generation, Bejan number.

\section{NOMENCLATURE}

A Surface area of the collector $\left(\mathrm{m}^{2}\right)$

$A_{e} \quad$ Area base on the perimeter of collector $\left(\mathrm{m}^{2}\right)$

$C \quad$ Constant defined in subsection 2.4

$C_{p} \quad$ Specific heat at constant pressure $\left(\mathrm{J} \mathrm{kg}^{-1} \mathrm{~K}^{-1}\right)$

$h \quad$ Convective heat transfer coefficient $\left(\mathrm{Wm}^{-2} \mathrm{~K}^{-1}\right)$ $h_{a} \begin{aligned} & \text { Convective heat transfer coefficient between glass and ambient air } \\ & \left(\mathrm{Wm}^{-2} \mathrm{~K}^{-1}\right)\end{aligned}$

I Intensity of solar radiation $\left(\mathrm{Wm}^{-2}\right)$

$A_{e} \quad$ Area base on the perimeter of collector $\left(\mathrm{m}^{2}\right)$

$k \quad$ Thermal conductivity $\left(\mathrm{W} \mathrm{m}^{-1} \mathrm{~K}^{-1}\right)$

$k_{b} \quad$ Back insulation conductivity $\left(\mathrm{Wm}^{-1} \mathrm{~K}^{-1}\right)$

$k_{e} \quad$ Edge insulation conductivity $\left(\mathrm{Wm}^{-1} \mathrm{~K}^{-1}\right)$

$m$ Mass flow rate $\left(\mathrm{Kg} \mathrm{s}^{-1}\right)$

$N \quad$ number of glass

\section{Greek symbols}

$\alpha \quad$ Fluid thermal diffusivity $\left(\mathrm{m}^{2} \mathrm{~s}^{-1}\right)$

$\beta \quad$ Tilt angle $\left({ }^{0}\right)$

$\lambda$ Transmitivity

$\phi \quad$ Nanoparticles volume fraction

$v \quad$ Kinematic viscosity $\left(\mathrm{m}^{2} \mathrm{~s}^{-1}\right)$

$\eta \quad$ Collector efficiency

$\theta \quad$ Dimensionless temperature

$\rho \quad$ Density $\left(\mathrm{kgm}^{-3}\right)$

$\mu \quad$ Dynamic viscosity $\left(\mathrm{Nsm}^{-2}\right)$

$\kappa \quad$ Absorption coefficient

Subscripts

a absorber

amb ambient 
R. Nasrin, M.A. Alim and M. Hasanuzzaman/Journal of Naval Architecture and Marine Engineering, 13(2016) 135-150

\begin{tabular}{|c|c|}
\hline $\mathrm{Nu}$ & Nusselt number \\
\hline$p$ & Pressure $\left(\mathrm{kg} \mathrm{m} \mathrm{s}^{-2}\right)$ \\
\hline $\operatorname{Pr}$ & Prandtl number \\
\hline$q$ & Heat flux $\left(\mathrm{Wm}^{-2}\right)$ \\
\hline $\operatorname{Re}$ & Reynolds number \\
\hline$T$ & Dimensional temperature $(\mathrm{K})$ \\
\hline$u$, & Dimensional $x$ and $y$ components of velocity $\left(\mathrm{m} \mathrm{s}^{-1}\right)$ \\
\hline$U$ & Dimensionless velocities \\
\hline$\stackrel{r}{U}_{l}$ & Overall heat transfer coefficient $\left(\mathrm{W} \mathrm{m} \mathrm{K}^{-2} \mathrm{~K}^{-1}\right)$ \\
\hline $\mathrm{V}$ & Magnitude of velocity $\left(\mathrm{m} \mathrm{s}^{-1}\right)$ \\
\hline$X$ & Dimensionless coordinates \\
\hline$x$ & Cartesian coordinates $(\mathrm{m})$ \\
\hline$x_{b}$ & Back insulation thickness $(m)$ \\
\hline$x_{e}$ & Edge insulation thickness $(m)$ \\
\hline
\end{tabular}

$\begin{array}{ll}a v & \text { average } \\ b & \text { bottom } \\ c o l & \text { collector } \\ e & \text { edge } \\ f & \text { fluid } \\ \text { in } & \text { input } \\ \text { loss } & \text { lost } \\ n f & \text { nanofluid } \\ \text { out } & \text { output } \\ r e c v & \text { received } \\ s & \text { solid particle } \\ t & \text { top } \\ u s f l & \text { useful } \\ 1 & \text { Cu nanoparticle } \\ 2 & \text { Ag nanoparticle }\end{array}$

\section{Introduction}

Today, renewable energy based power generation is broadly encouraged all over the world because of the limited non-renewable energy resources, environmental awareness, and abundant renewable resources Schroeder (2009), Hasanuzzaman et al. (2015) and Hosenuzzaman et al. (2015). Among the renewable energy, solar energy is one of the most potential resources Ahmed et al. (2013). Solar collector is one the key elements in many applications (i.e. building heating systems, solar drying devices, etc). Flat-plate solar collector is commonly used for low temperature solar thermal energy (i.e. solar water-heating systems, solar space heating etc.) where performance of the solar collector depends on the various parameters. Heat transfer process and performance of the solar collector has been investigated numerically and experimentally. Saleh (2012) simulated one-dimensional mathematical model for transient processes which occurs in liquid flat-plate solar collectors. Flat plate and heat pipe solar collectors with and without color absorbers are also numerically studied Kazeminejad (2002) and Azad (2009). Struckmann (2008) analyzed flat-plate solar collector where efforts had been made to combine a number of important factors into a single equation. Martín et al. (2011) experimentally studied heat transfer in enhanced flat-plate solar collectors. To test the enhanced solar collector and compare with a standard one, an experimental side-by-side solar collector test bed was designed and constructed. They concluded that the pressure loss ratio remained constant at about 1.8 for Reynolds numbers higher than 500 inside the raisers and increasing pumping power improved thermal efficiency. Sandhu (2013) experimentally studied temperature field in flat-plate collector and heat transfer enhancement with the use of insert devices. Various new configurations of the conventional insert devices were tested over a wide range of Reynolds number (200-8000). Testing of thermal efficiency, heat transfer system, and optimization of solar thermal collectors were addressed and discussed by Zambolin (2011). Karuppa et al. (2012) experimentally investigated a new solar flat plate collector. Experiments had been carried out to test the performance of both the water heaters under water circulation with a small pump. Their results showed that rising values of temperature difference between the outlet water and the ambient air decreased thermal efficiency due to heat loss.

Iordanou (2009) investigated flat-plate solar collectors for water heating with improved heat transfer for application in climatic conditions of the mediterranean region. Dara et al. (2013) conducted evaluation of a passive flat-plate solar collector and investigated the variations of top loss heat transfer coefficient with absorber plate emittance and air gap spacing between the absorber plate and the cover plate. Enhanced heat transfer using oscillatory flows in solar collectors, different geometric absorber configuration were analyzed by Lambert (2006) and Amrutkar (2012). Karanth et al. (2011) performed numerical simulation of a solar flat plate collector using discrete transfer radiation model (DTRM)-a CFD Approach. They concluded that temperature difference between absorber plate and fluid increased with increasing flow velocity and absorber plate temperature was almost linear at all considered values of Assisted convective heat transfer and entropy generation in a solar collector filled with nanofluid 
R. Nasrin, M.A. Alim and M. Hasanuzzaman/Journal of Naval Architecture and Marine Engineering, 13(2016) 135-150 flow velocities. Álvarez et al. (2010) studied finite element modelling of a solar collector and presented a mathematical model of a serpentine flat-plate solar collector using finite elements.

All thermofluidic processes involve irreversibilities and therefore incur an efficiency loss. In practice, the extent of these irreversibilities can be measured by the entropy generation rate. In designing practical systems, it is desirable to minimize the rate of entropy generation and to maximize the available energy Hooman et al. (2008), Delavar, and Hedayatpour (2012). The entropy generation induced by natural convection heat transfer in a square cavity was studied by Shahi et al. (2011) and found that the Nusselt number increased and the entropy generation reduced as the nanoparticle volume fraction was increased. Enhancement of collector thermal performance with different nanofluids was conducted Polvongsri and Kiatsiriroat (2011), Natarajan and Sathish (2009). Mahian et al. (2013-2014) performed review of the applications of nanofluids and entropy generation in solar energy. The effect of nanofluids on the performance of solar collectors was shown. Modeling of solar water collector of different shapes with water based nanofluids using various nanoparticles was conducted by Nasrin et al. (2013, 2014a-b, 2015). Hussein et al. (2012, 2014, 2015a-b, 2016a-c) studied computational analysis in heat transfer and entropy generation considering different types of geometry as well as solar collector in both two dimensional and three dimensional forms.

From the above discussion, it is clear that the application of nanofluid is one most potential options to enhance the heat transfer of the solar collector systems. As this is a potential field, a good number of research works have been conducted in the field and still have many scopes to work with fluid flow, heat transfer, enhancement of collector efficiency and entropy generation using different nanofluids. The aim of the paper is to investigate the heat transfer phenomena in term of heat transfer rate, velocity, collect efficiency, entropy generation and Bejan number by varying the solid nanoparticle volume fraction of water $/ \mathrm{Cu}$, water/ $\mathrm{Ag}$ and water/Cu/Ag nanofluids.

\section{Problem Formulation}

Figure 1 shows the schematic diagram of the collector. The numerical computation is carried on taking single riser pipe of FPSC. FPSC with single riser pipe gives the average heat transfer and fluid flow phenomena. The glass cover is at the top of the FPSC. It is highly transparent and anti-reflected. It is also called as glazing. The glass top surface is exposed to solar irradiation. The glass cover is made of borosilicate. It has thermal conductivity of 1.14 $\mathrm{W} / \mathrm{mK}$, specific heat of $750 \mathrm{~J} / \mathrm{kgK}$ and coefficient of sunlight transmission of $95 \%$. Thickness of glass cover is $0.005 \mathrm{~m}$. Air gap of $0.005 \mathrm{~m}$ lies between glass cover and absorber plate. Air density $=1.269 \mathrm{Kg} / \mathrm{m}^{3}$, specific heat $=$ $287.058 \mathrm{~J} / \mathrm{kgK}$ and thermal conductivity $=0.0243 \mathrm{~W} / \mathrm{mK}$. All these properties of air domain represent air of temperature at $298 \mathrm{~K}$. Length, width and thickness of the absorber plate are $1 \mathrm{~m}, 0.15 \mathrm{~m}$ and $0.0005 \mathrm{~m}$ respectively. Coefficients of heat absorption and emission of absorber plate are 95\% and 5\% respectively. The riser pipe has height $1 \mathrm{~m}$, inner diameter $0.01 \mathrm{~m}$ and thickness $0.0005 \mathrm{~m}$. A trapezium shaped bonding conductance is attached to the absorber and riser pipe. It is located from middle one-third part of width of the absorber plate.

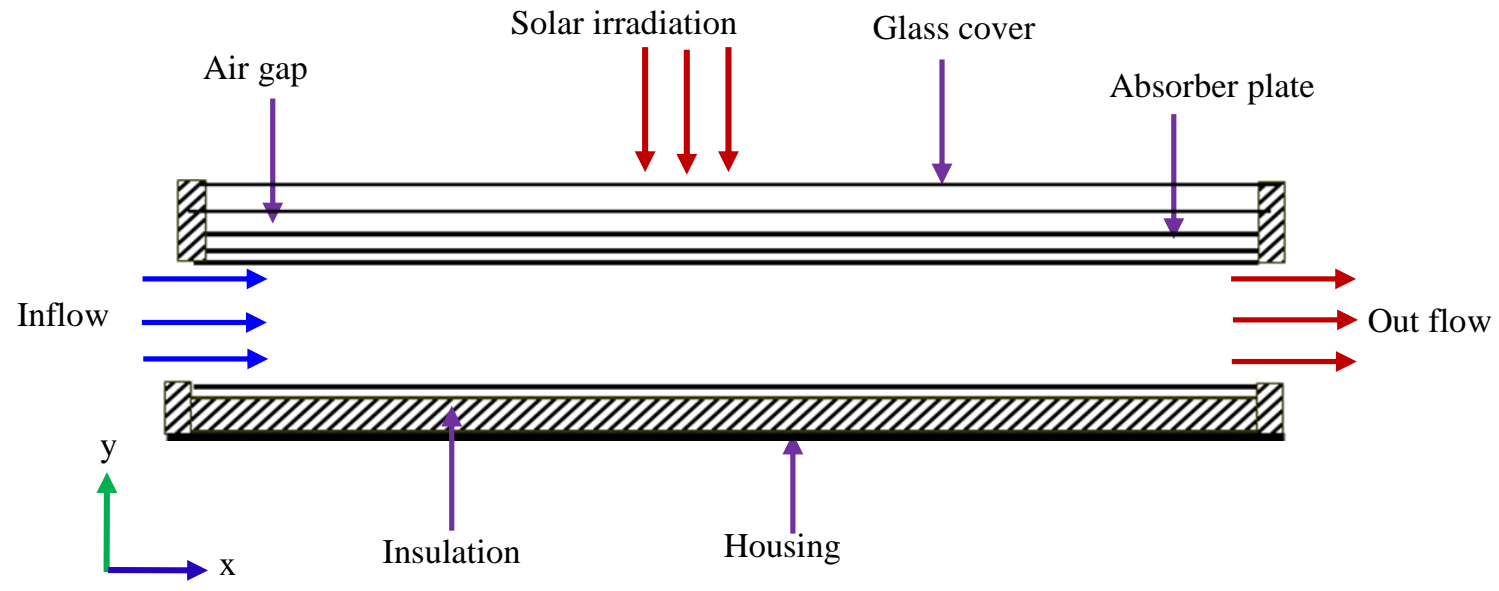

Figure 1: Longitudinal cross-section of a FPSC 
R. Nasrin, M.A. Alim and M. Hasanuzzaman/Journal of Naval Architecture and Marine Engineering, 13(2016) 135-150

It covers the three-fourth part of the riser pipe. It is as long as the absorber plate and tube. The absorber plate is modeled to provide for conduction, convection and radiation in the analysis. The absorber, riser and bonding conductance are made of copper metal. The computation domain is a fluid passing riser pipe which is attached ultrasonically to the absorber plate.

Let $I$ be the intensity of solar radiation and $A$ be any surface area, then the amount of energy received by any surface is: $Q_{i}=I . A$

This equation is modified for solar collector surface as it is the product of the rate of transmission of the cover $(\lambda)$ and the absorption rate of the absorber $(\kappa)$. Thus, $Q_{\text {recv }}=I(\lambda \kappa) A$

Then the temperature of absorber becomes higher than that of the surrounding. Some heat is lost to the atmosphere by convection and radiation. The rate of heat loss $\left(Q_{\text {loss }}\right)$ depends on the collector overall heat transfer coefficient $\left(U_{l}\right)$, the collector temperature $\left(T_{c o l}\right)$ and the surrounding ambient temperature $\left(T_{a m b}\right) \cdot Q_{\text {loss }}=U_{l} A\left(T_{\text {col }}-T_{\text {amb }}\right)$

The rate of useful energy $\left(Q_{u s f l}\right)$ is: $Q_{u s f l}=Q_{\text {recv }}-Q_{\text {loss }}=I(\lambda \kappa) A-U_{l} A\left(T_{c o l}-T_{\text {amb }}\right)$

It is also known that the rate of extraction of heat from the collector may be measured by means of the amount of heat carried away in the fluid passed through it. Thus $Q_{u s f l}=m C_{p}\left(T_{\text {out }}-T_{\text {in }}\right)$

where $m, C_{p}, T_{\text {in }}$ and $T_{\text {out }}$ are the mass flow rate per unit area, the specific heat at constant pressure, inlet and outlet fluid temperatures respectively.

To calculate the collector average temperature is difficult. The equation (4) may not be convenient. It is suitable to describe a quantity that communicates the actual useful energy gain of a collector to the useful gain if the whole collector surface is at the fluid inlet temperature. This quantity is known as "the collector heat removal factor $\left(F_{R}\right)$ " and is stated as: $\quad F_{R}==\frac{m C_{p}\left(T_{\text {out }}-T_{\text {in }}\right)}{A\left[I(\lambda \kappa)-U_{l}\left(T_{\text {in }}-T_{\text {amb }}\right)\right]}$

The expression of actual useful energy gain $\left(Q_{u s f l}\right)$ can be written as: $Q_{u s f l}=F_{R} A\left[I(\lambda \kappa)-U_{l}\left(T_{i n}-T_{a m b}\right)\right]$

The heat flux $q$ per unit area of absorber plate is $\frac{Q_{u_{s f l}}}{A}=q=I \lambda \kappa-U_{l}\left(T_{i n}-T_{a m b}\right)$.

The two dimensional governing equations are given as:

$\frac{\partial u}{\partial x}+\frac{\partial v}{\partial y}=0$

$\rho_{n f}\left(u \frac{\partial u}{\partial x}+v \frac{\partial u}{\partial y}\right)=-\frac{\partial p}{\partial x}+\mu_{n f}\left(\frac{\partial^{2} u}{\partial x^{2}}+\frac{\partial^{2} u}{\partial y^{2}}\right)$

$\rho_{n f}\left(u \frac{\partial v}{\partial x}+v \frac{\partial v}{\partial y}\right)=-\frac{\partial p}{\partial y}+\mu_{n f}\left(\frac{\partial^{2} v}{\partial x^{2}}+\frac{\partial^{2} v}{\partial y^{2}}\right)$

$u \frac{\partial T}{\partial x}+v \frac{\partial T}{\partial y}=\alpha_{n f}\left(\frac{\partial^{2} T}{\partial x^{2}}+\frac{\partial^{2} T}{\partial y^{2}}\right)$

$\left(\frac{\partial^{2} T_{a}}{\partial x^{2}}+\frac{\partial^{2} T_{a}}{\partial y^{2}}\right)=0$

where, $\rho_{n f}=(1-\phi) \rho_{f}+\phi \rho_{s}$ is the density,

$\left(\rho C_{p}\right)_{n f}=(1-\phi)\left(\rho C_{p}\right)_{f}+\phi\left(\rho C_{p}\right)_{s}$ is the heat capacitance,

$\mu_{n f}=\frac{\mu_{f}}{(1-\phi)^{2.5}}$ is the viscosity of Brinkman model (1952) 
$k_{n f}=k_{f} \frac{k_{s}+2 k_{f}-2 \phi\left(k_{f}-k_{s}\right)}{k_{s}+2 k_{f}+\phi\left(k_{f}-k_{s}\right)}$ is thermal conductivity of Maxwell Garnett model (1904)

$\alpha_{n f}=k_{n f} /\left(\rho C_{p}\right)_{n f}$ is the thermal diffusivity, $\operatorname{Pr}=\frac{v_{f}}{\alpha_{f}}$ is the Prandtl number and $\operatorname{Re}=\frac{U_{i n} H}{v_{f}}$ is the Reynolds number.

The boundary conditions are:

at all solid boundaries: $u=v=0$

at the solid-fluid interface: $k_{n f}\left(\frac{\partial T}{\partial y}\right)_{n f}=k_{\text {solid }}\left(\frac{\partial T_{a}}{\partial y}\right)_{\text {solid }}$

at the inlet boundary: $T=T_{\text {in }}, u=U_{\text {in }}$

at the outlet boundary: convective boundary condition $p=0$

at the top surface of absorber: heat flux $-k_{a} \frac{\partial T_{a}}{\partial y}=q=I \tau \kappa-U_{l}\left(T_{i n}-T_{a m b}\right)$

at outer surface of riser pipe: $\frac{\partial T}{\partial y}=0$

\subsection{Collector efficiency}

The instantaneous collector efficiency is:

$\eta=\frac{Q_{\text {usfl }}}{A I}=\frac{F_{R} A\left[I(\lambda \kappa)-U_{l}\left(T_{i n}-T_{a m b}\right)\right]}{A I}=F_{R}(\lambda \kappa)-F_{R} U_{l} \frac{\left(T_{i n}-T_{a m b}\right)}{I}$

\subsection{Average Nusselt number}

The average Nusselt number $(\mathrm{Nu})$ is expected to depend on a number of factors such as thermal conductivity, heat capacitance, viscosity, flow structure of nanofluids and volume fraction, dimensions and fractal distributions of nanoparticles. Equation of local Nusselt number for flow through the absorber tube of solar collector can be written as $\overline{N u}=\frac{U_{l} L}{k_{f}}=\frac{Q}{\Delta T}\left(\frac{L}{k_{f}}\right)=\frac{Q}{\left(q L / k_{f}\right)}\left(\frac{L}{k_{f}}\right)$

where $L$ is the length of riser pipe, $\Delta T$ is the difference between riser pipe surface temperature and ambient temperature, $Q$ is the energy received or lost by the absorber pipe surface. Due to assigned constant heat flux at absorber top surface and water based nanofluid flow this equation becomes $\overline{N u}=\frac{-k_{n f}\left(\frac{\partial T}{\partial y}\right)}{\left(q L / k_{f}\right)}\left(\frac{L}{k_{f}}\right)=-\left(\frac{k_{n f}}{k_{f}}\right)\left(\frac{k_{f}}{q}\right)\left(\frac{\partial T}{\partial y}\right)$

Dimensionless form of local Nusselt number at top of riser pipe is $\overline{N u}=-\frac{k_{n f}}{k_{f}} \frac{\partial \theta}{\partial Y}$.

The above equations are non-dimensionalized by using the following dimensionless dependent and independent variables:

$$
X=\frac{x}{L}, Y=\frac{y}{L}, U=\frac{u}{U_{\text {in }}}, V=\frac{v}{U_{\text {in }}}, \theta=\frac{\left(T-T_{\text {in }}\right) k_{f}}{q L}
$$


Thus rate of heat transfer at top surface of riser pipe according to Nasrin and Alim (2015) is as $N u=\int_{0}^{1} \overline{N u} d X$

Normalized Nusselt number is defined as the ratio of average Nusselt number at any volume fraction of nanoparticles to that of pure water, is $N u^{*}=\frac{N u(\phi)}{N u(\phi=0)}$

\subsection{Mean bulk temperature and velocity}

The mean bulk temperature and average sub domain velocity of the fluid inside the collector may be written as

$$
T_{a v}=\frac{\iint_{A} T d A}{\iint_{A} d A}=\frac{1}{H L} \iint_{A} T d A \text { and } \mathrm{V}_{a v}=\frac{\iint_{A} \mathrm{~V} d A}{\iint_{A} d A}=\frac{1}{H L} \iint_{A} \mathrm{~V} d A .
$$

\subsection{Overall heat transfer coefficient}

The overall heat transfer loss from the collector is the summation of three separate components, the top loss coefficient, the bottom loss coefficient and the edge loss coefficient. The empirical relations for these coefficients are mentioned by Duffie and Beckman (1991) as follows: $U_{l}=U_{t}+U_{b}+U_{e}$ where

$$
U_{t}=\left\{\frac{N}{\frac{C}{T_{a}}\left[\frac{T_{a}-T_{a m b}}{N+f}\right]^{c}}+\frac{1}{h_{a m b}}\right\}^{-1}+\frac{\sigma\left(T_{a}+T_{a m b}\right)\left(T_{a}^{2}+T_{a m b}^{2}\right)}{\left(\varepsilon_{a}+0.00591 N h_{a m b}\right)^{-1}+\frac{2 N+f-1+0.13 \varepsilon_{a}}{\varepsilon_{c}}-N},
$$

$U_{b}=\frac{k_{b}}{x_{b}}$

$U_{e}=\frac{U_{e} A_{e}}{A}=\frac{k_{e}}{x_{e}}\left[\frac{2(L+W) H}{L W}\right]$ and

$C=520 *\left(1-0.000051 \beta^{2}\right)$

$f=\left(1+0.089 h_{a}-0.1166 h_{a m b} \varepsilon_{a}\right) *(1+0.07866 N)$ and

$e=0.43 *\left(1-\left(100 / T_{a m}\right)\right)$

\subsection{Entropy generation}

The entropy generation in the flow field is caused by the non-equilibrium flow imposed by boundary conditions. In the convection process, the entropy generation is due to the irreversibility caused by the heat transfer phenomena and fluid flow friction. According to Bejan (1996), the dimensional local entropy generation, $s_{\text {gen }}$, can be expressed by:

$s_{g e n}=\frac{k_{n f}}{T_{0}^{2}}\left[\left(\frac{\partial T}{\partial x}\right)^{2}+\left(\frac{\partial T}{\partial y}\right)^{2}\right]+\frac{\mu_{n f}}{T_{0}}\left[2\left(\frac{\partial u}{\partial x}\right)^{2}+2\left(\frac{\partial v}{\partial y}\right)^{2}+\left(\frac{\partial u}{\partial x}+\frac{\partial v}{\partial y}\right)^{2}\right]$

where $T_{0}=\frac{T_{c o l}+T_{i n}}{2}$.

In equation (19), the first term represents the dimensional entropy generation due to heat transfer $\left(s_{\text {gen,h }}\right)$, while the second term represents the dimensional entropy generation due to viscous dissipation ( $\left.s_{\text {gen,v }}\right)$. By using 
dimensionless parameters presented in Eq. (18), the expression of the non-dimensional entropy generation, $S_{g e n}$ can be written by:

$$
\begin{aligned}
& S_{\text {gen }}=s_{\text {gen }} \frac{T_{0} L^{2}}{k_{f}\left(T_{c o l}-T_{i n}\right)^{2}} \\
& =\frac{k_{n f}}{k_{f}}\left[\left(\frac{\partial \theta}{\partial X}\right)^{2}+\left(\frac{\partial \theta}{\partial Y}\right)^{2}\right]+\chi \frac{\mu_{n f}}{\mu_{f}}\left[2\left(\frac{\partial U}{\partial X}\right)^{2}+2\left(\frac{\partial V}{\partial Y}\right)^{2}+\left(\frac{\partial U}{\partial X}+\frac{\partial V}{\partial Y}\right)^{2}\right] \\
& =S_{g e n, h}+S_{g e n, v}
\end{aligned}
$$

Here $S_{g e n, h}$ and $S_{g e n, v}$ are the dimensionless entropy generation for heat transfer and viscous effect respectively. In Eq. (20), $\chi$ is the irreversibility factor which represents the ratio of the viscous entropy generation to thermal entropy generation. It is given as:

$$
\chi=\frac{T_{0} \mu_{f}}{k_{f}} \frac{U_{i}^{2}}{\left(T_{c o l}-T_{i n}\right)^{2}}
$$

The dimensionless average entropy generation, $S$ for the entire computational domain is as follows:

$$
S=\frac{1}{\bar{V}} \int S_{g e n} d \bar{V}=S_{g e n, h, m}+S_{g e n, v, m}
$$

where $\bar{V}$ is the volume occupied by the nanofluid and $S_{g e n, h, m}$ and $S_{g e n, v, m}$ are the average entropy generation for heat transfer and viscous effect respectively.

Normalized entropy generation can be written as $S^{*}=\frac{S(\phi)}{S(\phi=0)}$

\subsection{Bejan number}

The Bejan number, $B e$, defined as the ratio between the entropy generation due to heat transfer by the total entropy generation, is expressed as $B e=\frac{S_{g e n, h, m}}{S}$

It is known that the heat transfer irreversibility is dominant when $B e$ approaches to 1 . When $B e$ becomes much smaller than $1 / 2$ the irreversibility due to the viscous effects dominates the processes and if $B e=1 / 2$ the entropy generation due to the viscous effects and the heat transfer effects are equal Khorasanizadeh et al. (2013).

\section{Numerical Implementation}

The Galerkin finite element method of Reddy and Gartling (1994) is used to solve the governing equations (8) - (12) along with convective boundary condition for the considered problem. Conservation equations are solved for the finite element method to yield the velocity and temperature fields for the water flow in the absorber tube and the temperature field for the absorber plate. The equation of continuity has been used as a constraint due to mass conservation and this restriction may be used to find the pressure distribution. Then the velocity components $(u, v)$ and temperatures $\left(T, T_{a}\right)$ of governing equations (8) - (12) are expanded using a basis set. The Galerkin finite element technique yields the subsequent nonlinear residual equations. Gaussian quadrature technique is used to evaluate the integrals in these equations. The non-linear residual equations are solved using Newton-Raphson method to determine the coefficients of the expansions. The convergence of solutions is assumed when the relative error for each variable between consecutive iterations is recorded below the convergence criterion such that $\left|\psi^{n+1}-\psi^{n}\right| \leq 1.0 \mathrm{e}^{-6}$, where $n$ is the number of iteration and $\Psi$ is a function of any one of $u, v, T$ and $T_{a}$.

\subsection{Mesh generation}

The finite element meshing of the computational domain is displayed by the figure 2. Extra fine meshing is chosen for this geometry. 


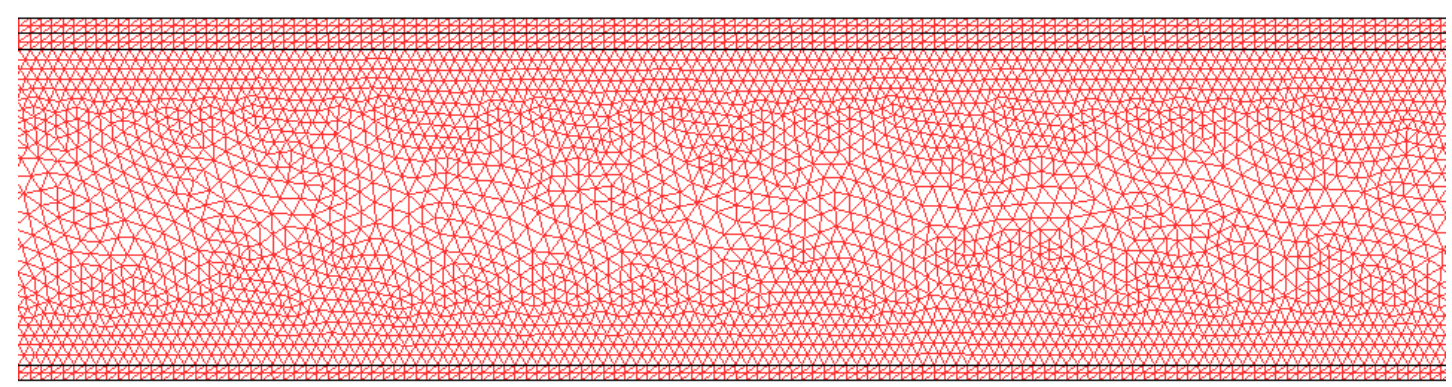

Figure 2: Mesh generation of the 2D domain

\subsection{Grid check}

A grid-independent check is performed at $\operatorname{Pr}=5.8, I=215 \mathrm{~W} / \mathrm{m}^{2}$ and $R e=480$ for a FPSC. Five different nonuniform grid systems are checked with the number of elements: 42,010, 99,832, 1,50,472, 1,68,040 and 1,92,548. Heat transfer rate for water-copper nanofluid $(\phi=2 \%)$ as well as water $(\phi=0 \%)$ is considered as supervising parameter. It is noticed from the fifth and sixth column of Table 1 that there is no considerable alteration in the value of mean Nusselt number but time unbearable. Thus 1,68,040 elements are considered for numerical analysis.

Table 1: Grid Sensitivity Check at $\operatorname{Pr}=5.8, I=215 \mathrm{~W} / \mathrm{m}^{2}$ and $R e=480$

\begin{tabular}{|c|c|c|c|c|c|}
\hline Elements & 42,010 & 99,832 & $1,40,472$ & $\mathbf{1 , 6 8 , 0 4 0}$ & $1,92,548$ \\
\hline$N u$ (Nanofluid) & 1.87872 & 1.99127 & 2.10934 & $\mathbf{2 . 1 4 3 5 1}$ & 2.14378 \\
\hline$N u$ (Water) & 1.59326 & 1.69225 & 1.81524 & $\mathbf{1 . 8 4 3 3 3}$ & 1.84341 \\
\hline Time (s) & 127.52 & 308.75 & 581.11 & $\mathbf{8 9 7 . 2 3}$ & 1295.31 \\
\hline
\end{tabular}

\subsection{Thermo-physical properties}

The thermo-physical properties of the nanoparticle are taken from Nasrin and Alim (2014) and given in Table 2.

Table 2: Thermo-physical properties of fluid and nanoparticles

\begin{tabular}{cccc}
\hline Physical Properties & Fluid phase (Water) & $\mathrm{Ag}$ & $\mathrm{Cu}$ \\
\hline$C_{p}(\mathrm{~J} / \mathrm{kgK})$ & 4179 & 235 & 385 \\
$\rho\left(\mathrm{kg} / \mathrm{m}^{3}\right)$ & 997.1 & 10500 & 8933 \\
$k(\mathrm{~W} / \mathrm{mK})$ & 0.613 & 429 & 400 \\
$\alpha \times 10^{7}\left(\mathrm{~m}^{2} / \mathrm{s}\right)$ & 1.47 & 1738.6 & 1163.1 \\
$\mu \times 10^{6}\left(\mathrm{Ns} / \mathrm{m}^{2}\right)$ & 855 & --- & ---- \\
\hline
\end{tabular}

\subsection{Nanofluid with double nanoparticles}

Water based nanofluid with copper and silver nanoparticles is also used as heat transfer medium in this numerical computation. For this the effective properties of nanofluid that is equations (13-16) can be modified as:

The effective thermal diffusivity $\alpha_{n f}=k_{n f} /\left(\rho C_{p}\right)_{n f}$

effective density $\rho_{n f}=\left(1-\phi_{1}-\phi_{2}\right) \rho_{f}+\phi_{1} \rho_{s 1}+\phi_{2} \rho_{s 2}$

the effective heat capacitance 
$\left(\rho C_{p}\right)_{n f}=\left(1-\phi_{1}-\phi_{2}\right)\left(\rho C_{p}\right)_{f}+\phi_{1}\left(\rho C_{p}\right)_{s 1}+\phi_{2}\left(\rho C_{p}\right)_{s 2}$

the effective dynamic viscosity (modified form) of Brinkman model (1952)

$\mu_{n f}=\mu_{f}\left(1-\phi_{1}-\phi_{2}\right)^{-2.5}$

and the effective thermal conductivity (modified form) of Maxwell Garnett model (1904)

$k_{n f}=k_{f} \frac{\left(k_{s 1}+k_{s 2}\right)+2 k_{f}-2 \phi_{1}\left(k_{f}-k_{s 1}\right)-2 \phi_{2}\left(k_{f}-k_{s 2}\right)}{\left(k_{s 1}+k_{s 2}\right)+2 k_{f}+\phi_{1}\left(k_{f}-k_{s 1}\right)+\phi_{2}\left(k_{f}-k_{s 2}\right)}$

where suffixes 1 and 2 represent two types of nanoparticles such as $\mathrm{Cu}$ and $\mathrm{Ag}$ respectively.

\section{Results and Discussion}

Rate of heat transfer, average bulk temperature, mean sub domain velocity, mean output temperature, percentage of collector efficiency, mean entropy generation, Bejan number, normalized Nusselt number, normalized entropy generation are shown graphically for various values of solid volume fraction $(\phi)$ of the water/ $\mathrm{Cu}$, water/Ag and water/Cu/Ag nanofluids. The considered values of $\phi$ are $0 \%, 1 \%, 2 \%$ and $3 \%$. The Reynolds number $(R e)=480$, surface area of collector $(A)=1.8 \mathrm{~m}^{2}$, mass flow rate per unit area $(m)=0.0248 \mathrm{Kg} / \mathrm{s}$, overall heat transfer coefficient $\left(U_{l}\right)=8 \mathrm{~W} / \mathrm{m}^{2} \mathrm{~K}$, solar irradiation $(I)=215 \mathrm{~W} / \mathrm{m}^{2}$ and Prandtl number $(P r)=5.8$ are chosen fixed.

\subsection{Rate of heat transfer}

The $\mathrm{Nu}-\phi$ profile for water-Cu, water- $\mathrm{Ag}$ and water-Cu/Ag nanofluids as well as base fluid are depicted in the figure 3. The distribution of $\phi\left(=\phi_{1}+\phi_{2}\right)$ for water based nanofluid having copper and silver nanoparticles is as $\phi=\phi_{1}+\phi_{2}$ $=0.05 \%+0.05 \%=1 \%$ and so on.

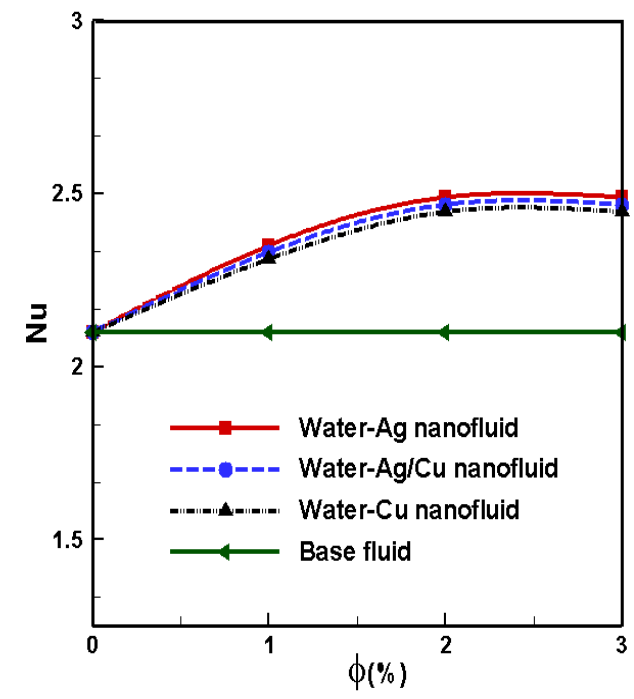

Figure 3: Mean Nusselt number for effect of solid volume fraction

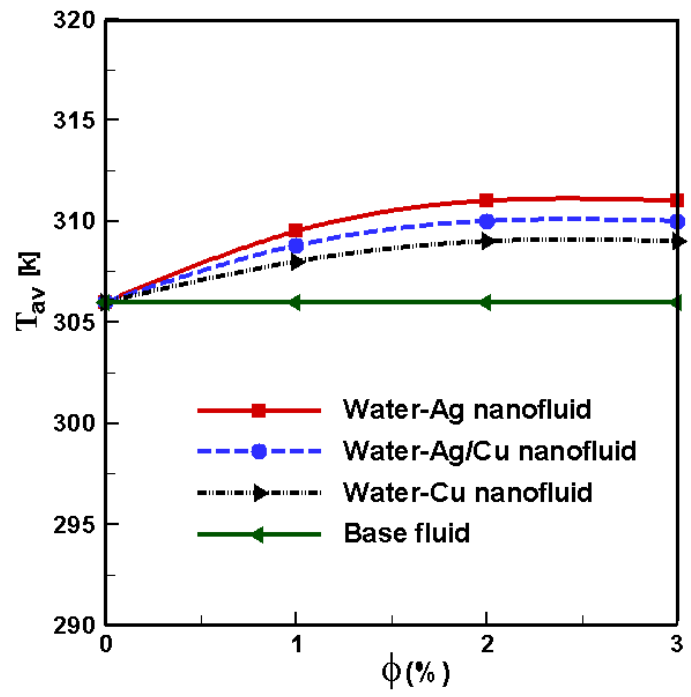

Figure 4: Average bulk temperature for effect of solid concentration

From the plot of the average Nusselt number $(\mathrm{Nu})$-solid volume fraction $(\phi)$ shows that rate of heat transfer rises monotonically upto $2 \%$ of solid volume fraction of all nanofluids. And then there is almost no change in $N u-\phi$ profile for extra variation of $\phi$ from $2 \%$ to $3 \%$. It is happened due to lower value of heat capacitance of nanofluid. Here rate of heat transfer remains constant for clear water $(\phi=0 \%)$ with the variation of $\phi$. Heat transfer rate increases by $16 \%, 18 \%$ and $17 \%$ with the variation of $\phi$ from $0 \%$ to $2 \%$ of water-Cu, water- $\mathrm{Ag}$ and water-Cu/Ag 
nanofluids respectively. Thus, adding more nanoparticles is not beneficial because of increasing nanoparticles concentration increases viscosity. On the other hand heat capacitance of nanofluid is lower than base fluid.

\subsection{Average bulk temperature}

Average bulk temperature $\left(\theta_{a v}\right)$ for the effect of the solid volume fraction is shown in the figure 4 . $\theta_{a v}$ grows successively for $\phi$ upto $2 \%$. Mean temperature remains constant for further increasing of solid volume fraction. It is well known that higher concentration of solid particle enhances thermal conductivity as well as temperature of the working nanofluids. Figure 4 expresses that mean bulk temperature of water/silver nanofluid becomes greater than water/ $\mathrm{Ag} / \mathrm{Cu}$ and water/Cu nanofluid.

\subsection{Mean velocity}

Mean sub-domain velocity $\left(\mathrm{V}_{\mathrm{av}}\right)$ against solid volume fraction of different nanofluids is expressed in the figure 5 . $\mathrm{V}_{\mathrm{av}}$ has notable changes with different values of solid concentration. Growing $\phi$ devalues mean velocity of the nanofluid through the riser pipe of the flat plate solar collector. This happens because more solid concentrated nanofluid can't move freely like base fluid water. Greater $\phi$ represents higher thermal conductivity simultaneously higher density properties of the nanofluid. Thus motion of the nanofluid diminishes with enhancing $\phi$. Velocity of copper/water nanofluid is higher than other nanofluids. This is due to the fact that density of water/Cu nanofluid is lower than other nanofluids.

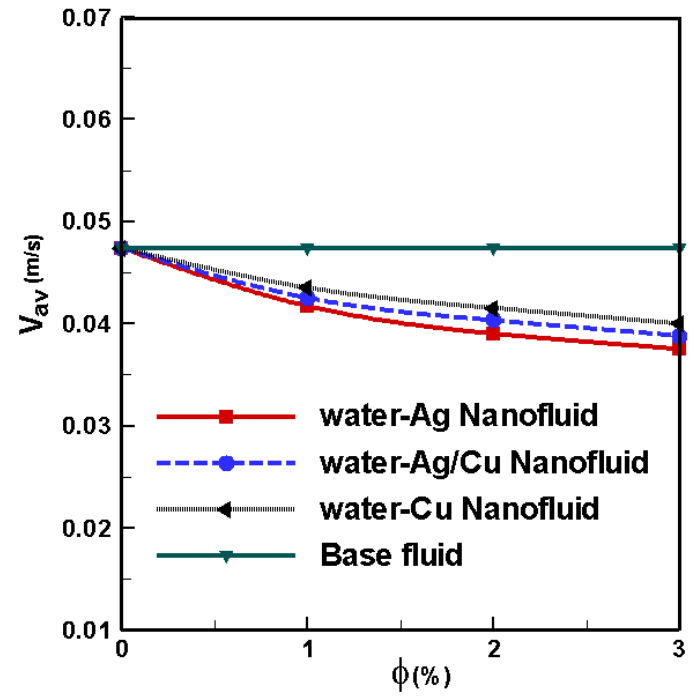

Figure 5: Mean velocity for effect of solid concentration

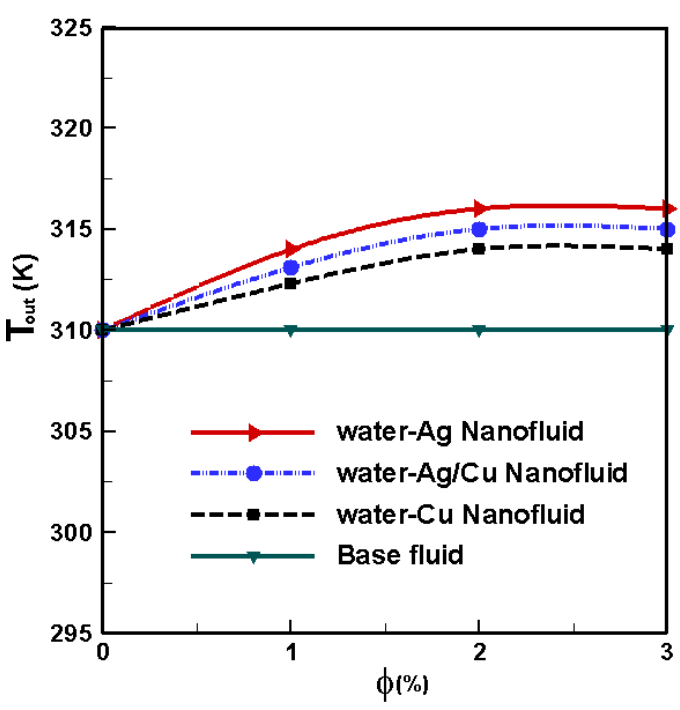

Figure 6: Mean outlet temperature for the effect of solid concentration

\subsection{Average outlet temperature}

Figure 6 displays the mean output temperature $\left(T_{\text {out }}\right)$ of different nanofluids with the influences of volume fraction. From this figure it is shown that the inlet temperature of fluid is maintained at $300 \mathrm{~K}$ and then it increases gradually with the contact of heated solid riser pipe. And finally the mean output temperature is obtained as $310 \mathrm{~K}$, $312 \mathrm{~K}$, $314 \mathrm{~K}$ and $314 \mathrm{~K}$ for water/Cu, $310 \mathrm{~K}, 314 \mathrm{~K}, 316 \mathrm{~K}$ and $316 \mathrm{~K}$ for water/Ag, $310 \mathrm{~K}, 313 \mathrm{~K}, 315 \mathrm{~K}$ and $315 \mathrm{~K}$ for water/Cu/Ag nanofluid at $\phi=0 \%, 1 \%, 2 \%$, and $3 \%$ respectively. $T_{\text {out }}$ remains unchanged for $\phi=3 \%$.

\subsection{Collector efficiency}

The variation of percentage of collector efficiency as a function of the solid volume fraction varies from $0 \%-3 \%$ that is shown in figure 7. It is observed that increasing solid volume fraction (upto 2\%) enhances the collector efficiency. 
R. Nasrin, M.A. Alim and M. Hasanuzzaman/Journal of Naval Architecture and Marine Engineering, 13(2016) 135-150 The enhancement of collector efficiency is found from $40 \%$ to $48 \%$ for $\mathrm{Cu} / \mathrm{water}, 40 \%$ to $53 \%$ for $\mathrm{Ag} / \mathrm{water}$ and $40 \%$ to $51 \%$ for $\mathrm{Cu} / \mathrm{Ag} /$ water nanofluids in the case with the variation of $\phi$ from $0 \%-2 \%$ respectively. Mean output temperature of nanofluids has not been increased at $3 \%$ concentration. Consequently thermal efficiency has been decreased at $\phi=3 \%$ for all nanofluids. This result agrees the formula of thermal efficiency. So thermal efficiency has not been improved for further mixing nanoparticles with clear water.

\subsection{Mean entropy generation}

The variations of average entropy generation $(S)$ against solid volume fraction $(\phi)$ is displayed in the figure 8 . The entropy generation increases by $\phi$ upto $2 \%$. The increment of nanoparticles, in terms of enhancing heat transfer rate, observed in figure 3 is also obtained in terms of increasing entropy production. This result is to be expected since the addition of a greater concentration of nanoparticles increases the thermal conductivity and viscosity of the working fluid. The higher thermal conductivity results in a smaller temperature gradient within the riser pipe of the flat plate solar collector. Thus the average entropy generation caused by heat transfer irreversibility increases. The greater viscosity of the working fluid increases the local entropy generation due to fluid friction irreversibility. After the level of $\phi=2 \%$, there is no change in mean entropy generation for all types of nanofluids.

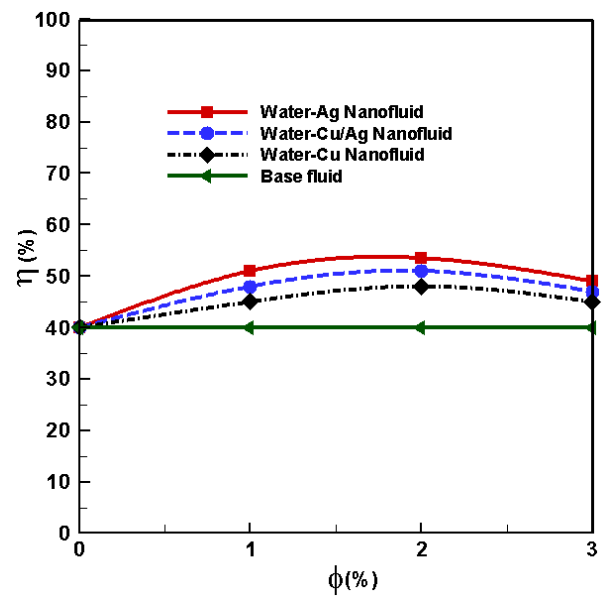

Figure 7: Collector efficiency for the effect of solid concentration

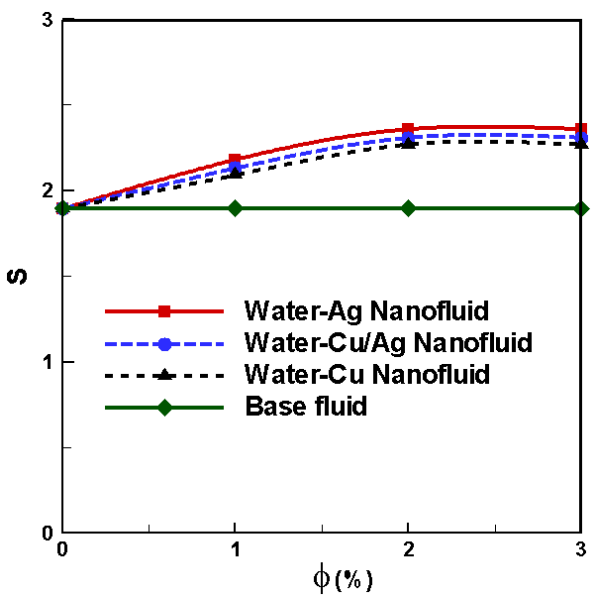

Figure 8: Mean entropy generation for the effect of solid concentration

\subsection{Bejan number}

Figure 9 depicts $B e-\phi$ profile for the considered values of $\phi$ from $0 \%$ to $3 \%$. Increasing $B e$ is observed for increasing solid volume fraction of nanoparticles within the level $0 \%$ to $2 \%$. For further increment of $\phi$ no variation is found in the Bejan number for different nanofluids. If the Bejan number $(B e)$ approaches unity, the fluid friction irreversibility effect can be ignored. In other words, mean entropy generation is dominated by the heat transfer irreversibility effect. Note that lower value of $B e$ is observed for base fluid.

\subsection{Normalized Nusselt number}

The variation of normalized Nusselt number against $\phi$ is displayed in the figure $10 . N u^{*}$ is the ratio of mean Nusselt number for nanofluid and base fluid. From the figure 3, it is seen that $N u$ - $\phi$ profile increases, so $N u^{*}-\phi$ profile also grows up with the variation of $\phi$ from $0 \%$ to $2 \%$ for all nanofluids. Values of normalized Nusselt number are found higher for the variation of water/Ag nanofluid than other considered nanofluids. 


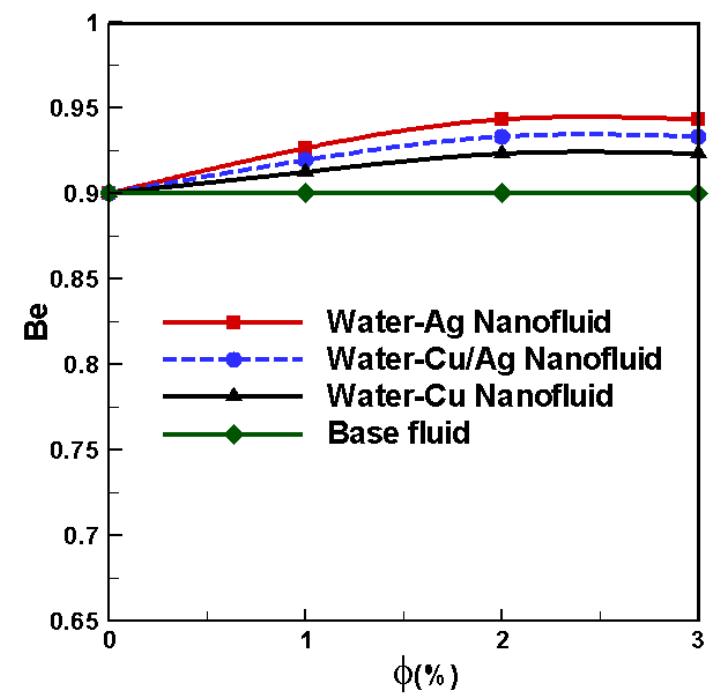

Figure 9: Bejan number for the effect of solid concentration

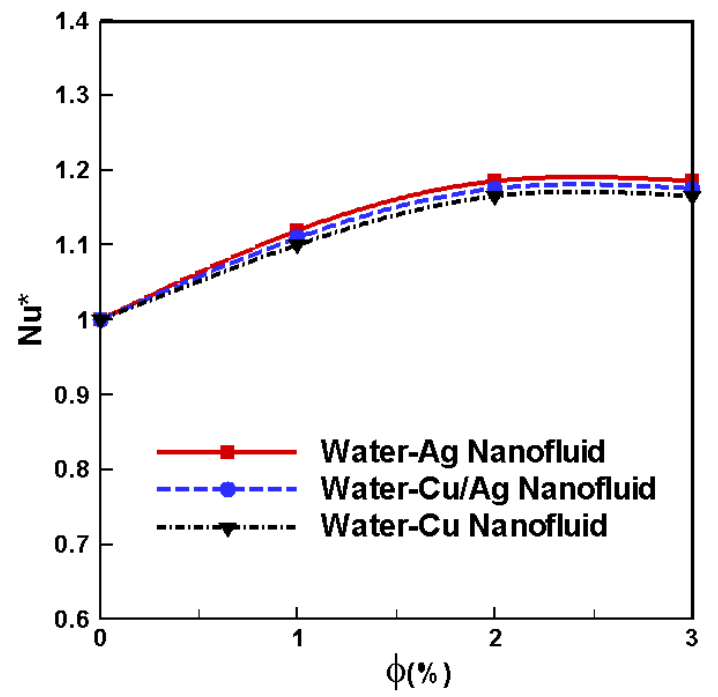

Figure 10: Normalized Nusselt number for the effect of solid concentration

\subsection{Normalized entropy generation}

Figure 11 displays the variations of normalized entropy generation against solid volume fraction. $S^{*}$ is high for higher solid volume fraction upto $2 \%$ which is similar to the figure 8 for water/Cu, water/Ag and water/Cu/Ag nanofluids.

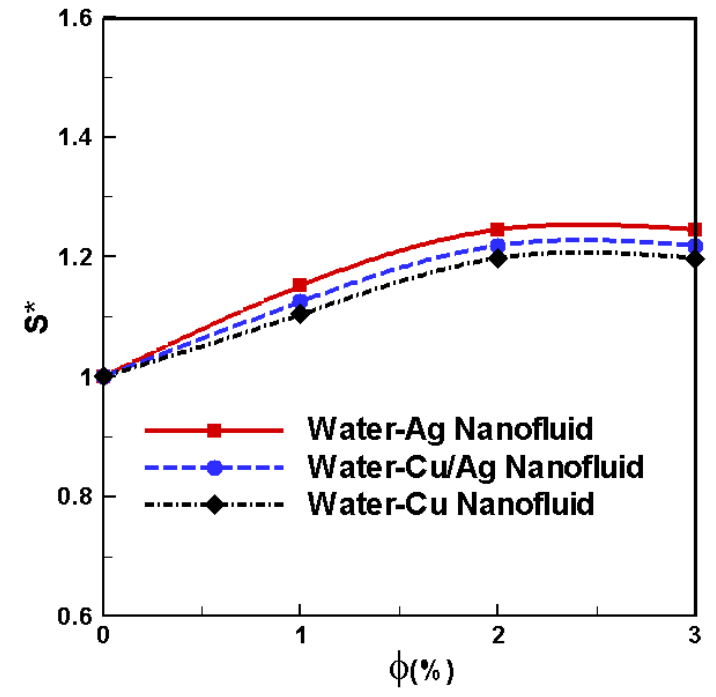

Figure 11: Normalized entropy generation for the effect of solid concentration

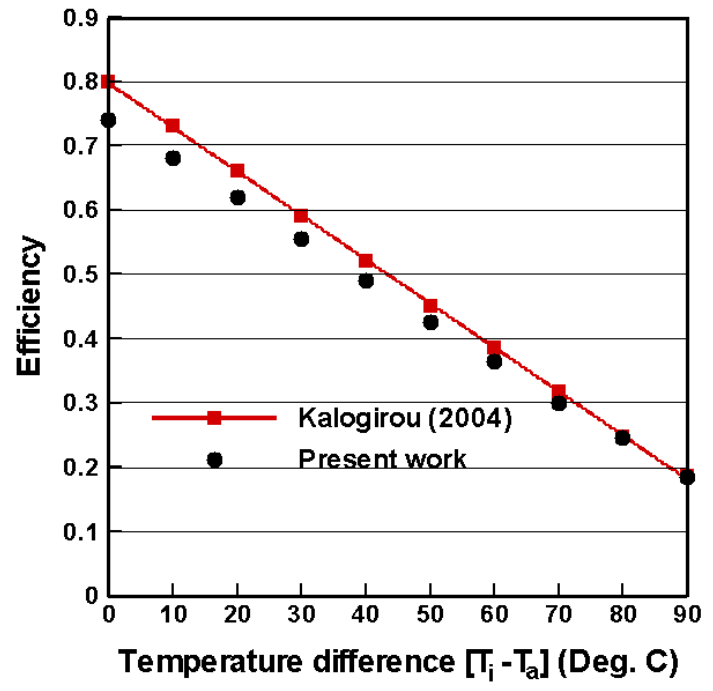

Figure 12: Comparison between present code and Kalogirou (2004)

\section{Correlation}

From the current two dimensional numerical study the calculated average Nusselt number $(\mathrm{Nu})$ and Bejan number (Be) are correlated with solid volume fraction $(\phi)$ of water/Ag nanofluid in the range of $0 \% \leq \phi \leq 2 \%$ through the FPSC. These correlations can be written as: 
R. Nasrin, M.A. Alim and M. Hasanuzzaman/Journal of Naval Architecture and Marine Engineering, 13(2016) 135-150

$N u=2.102 *(\phi)^{0.16}$, where the confidence coefficient is $r^{2}=99.8 \%$

and $B e=0.899 *(\phi)^{0.042}$, where the confidence coefficient is $r^{2}=99.9 \%$.

\section{Tilt Angle for Dhaka City}

The sun's position on the celestial sphere is usually specified in terms of the solar azimuth angle $\psi$ and the solar altitude angle $\alpha$. The solar zenith angle $\varphi$ is the sun's angular distance from the zenith, which is the point directly overhead on the celestial sphere. Thus $\varphi$ and $\alpha$ are complementary angles. The tilt angle is just the angle at which the surface is inclined from horizontal and is taken positive for south facing surfaces.

The solar altitude and azimuth angles are computed for any time, date and location using the formula: $\alpha=90^{\circ}-\varphi+\delta$, where $\varphi$ is the latitude taken north of the equator and $\delta$ is declination angle.

Another form of $\delta$ is $\delta=23.45^{\circ} \sin \left[\frac{360}{365}(284+d)\right]$, where $d$ is the day of the year like from 1 to 365 .

For the incident ray to be perpendicular to the surface is: $\alpha+\beta=90^{\circ}$, where $\alpha$ is elevation angle and $\beta$ is tilt angle of the solar collector measured from the horizontal surface.

Then from above equation it is clear that $\beta=\varphi-\delta$

For Dhaka city latitude and longitude are $23.7^{\circ} \mathrm{N}$ and $90.41^{0} \mathrm{E}$. The tilt angle will be

a) For May 25, 2015 (Summer), $d=31+28+31+30+25=145$.

$$
\begin{aligned}
& \text { So, } \delta=20.916^{0} \\
& \text { Now } \beta=\varphi-\delta=23.7^{0}-20.916^{0}=2.78^{0}
\end{aligned}
$$

b) For October 3, 2015 (Autumn), $d=276$.

$$
\begin{aligned}
& \text { So, } \delta=-5.007^{0} \\
& \text { Now } \beta=\varphi-\delta=23.7^{0}-\left(-5.007^{0}\right)=28.707^{0}
\end{aligned}
$$

Similarly, the tilt angle of solar collector for 365 days in Dhaka city is calculated and average value is obtained as $23.8^{0}$. As $\beta$ is positive, collector will be facing south. Maximum yearly solar radiation can be achieved using a tilt angle approximately equal to a site's latitude. To optimize performance in winter, collector can be tilted $15^{\circ}$ greater than the latitude. To optimize performance in summer, collector can be tilted $15^{\circ}$ less than the latitude.

\section{Comparison}

The current numerical result is compared for collector efficiency - temperature difference $\left[T_{i}-T_{a}\right]$ profile of water with the graphical representation of Kalogirou (2004) of flat plate solar thermal collector. $T_{i}$ and $T_{a}$ are temperatures of input fluid and ambient air respectively. The computation is done taking heat transfer medium as water with irradiation level $1000 \mathrm{~W} / \mathrm{m}^{2}$ and the mass flow rate per unit area $0.015 \mathrm{~kg} / \mathrm{s}$. A survey report on various types of solar thermal collectors and applications was presented by Kalogirou (2004). Author presented that generally the collector efficiency linearly depended on temperature difference for a FPSC. Figure 12 demonstrates the above stated comparison.

\section{Conclusion}

The influences of solid volume fraction of different nanofluids on forced convection boundary layer flow inside the riser pipe of a flat plate solar collector is accounted. Various $\phi$ have been considered for the heat transfer rate, mean bulk temperature, average velocity, mean output temperature and collector efficiency through the solar collector. The results of the numerical analysis lead to the following conclusions: 
R. Nasrin, M.A. Alim and M. Hasanuzzaman/Journal of Naval Architecture and Marine Engineering, 13(2016) 135-150

- $\quad$ Rate of heat transfer enhancement about $19 \%$ for $\mathrm{Ag} /$ water nanofluid with $\phi=2 \%$.

- Collector efficiency increases about $13 \%$ for $2 \%$ solid volume fraction using water/Ag nanofluid.

- Mean temperature increases for all nanofluids with increasing the $\phi$ upto $2 \%$.

- Average velocity $\mathrm{Cu} /$ water nanofluid is higher than other considered nanofluids.

- Mean entropy generation is obtained higher for $2 \%$ concentrated nanofluids.

- Bejan number is found higher for water/Ag nanofluid than other heat transfer medium.

- Adding double nanoparticles (silver and copper) with base fluid is more effective in enhancing performance of heat transfer rate and percentage of thermal efficiency than that of single nanoparticle (copper). Mean subdomain velocity is lower for nanofluid with double nanoparticles than nanofluid with single nanoparticle.

- Average tilt angle of collector is about $23.8^{0}$ in Dhaka city.

\section{References}

Ahmed, F., Al Amin, A.Q., Hasanuzzaman, M., Saidur. R. (2013): Alternative energy resources in Bangladesh and future prospect, Renew. Sust. Energ. Rev. 25, 698-707. https://doi.org/10.1016/j.rser.2013.05.008

Álvarez, A., Mu-iz, M.C., Varela, L.M., Cabeza, O. (2010): Finite element modelling of a solar collector, Int. Conf. on Renew. Energies and Power Quality, Granada (Spain).

Amrutkar, S.K., Ghodke, S., Patil, Dr.K.N. (2012): Solar flat plate collector analysis, IOSR J. of Engg., 2, 2 , 207 213.

Azad, E. (2009): Interconnected heat pipe solar collector, IJE Transactions A: Basics, 22, 3, 233.

Bejan, A. (1996): Entropy generation minimization: the method of thermodynamic optimization of finite-size systems and finite-time processes, Boca Raton, CRC Press.

Brinkman, H.C. (1952): The viscosity of concentrated suspensions and solution, Jounal of Chemical Physics, 20, 571-581. https://doi.org/10.1063/1.1700493

Chand, R., Rana, G. and Hussein, A. (2015): On the onset of thermal instability in a low Prandtl number nanofluid layer in a porous medium, J. of Appl. Fluid Mech., 8, 2, 265-272.

Delavar, M.A., Hedayatpour, M. (2012): Forced convection and entropy generation inside a channel with a heatgenerating porous block, Heat Transf.-Asian Res., 41 (7), 580-600.

Duffie, J.A. and Beckman, W.A. (1991): Solar Engineering of Thermal Processes, Toronto, John Wiley, 1991.

Ghachem, K., Kolsi, L., Mâatki, C., Hussein, A. and Borjini, M. (2012): Numerical simulation of three-dimensional double diffusive free convection flow and irreversibility studies in a solar distiller, Int. Commun. in Heat and Mass Trans., 39, 869-876. https://doi.org/10.1016/j.icheatmasstransfer.2012.04.010

Hasanuzzaman, M., Al-Amin, A.Q., Khanam, S., Hosenuzzaman, M. (2015): Photovoltaic power generation and its economic and environmental future in Bangladesh, J. Renew. Sust. Energ. 7, 1, 013108.

Hooman, K., Ejlali, A., Hooman, F. (2008): Entropy generation analysis of thermally developing forced convection in fluid-saturated porous medium, Appl. Math. Mech.-Engl. Ed., 29(2), 229-237. https://doi.org/10.1007/s10483008-0210-1

Hosenuzzaman, M., Rahim, N.A., Selvaraj, J., Hasanuzzaman, M., Mallek, A.B.M.A. (2015): A. Nahar, Global prospects, progress, policies, and environmental impact of solar photovoltaic power generation, Renew. Sust. Energ. Rev. 41, 284-297. https://doi.org/10.1016/j.rser.2014.08.046

Hussein, A. (2015): Applications of nanotechnology in renewable energies- A comprehensive overview and understanding, Renew. and Sust. Energy Rev., 42, 460-476. https://doi.org/10.1016/j.rser.2014.10.027 
R. Nasrin, M.A. Alim and M. Hasanuzzaman/Journal of Naval Architecture and Marine Engineering, 13(2016) 135-150

Hussein, A. (2016): Applications of nanotechnology to improve the performance of solar collectors - Recent advances and overview, Renew. and Sust. Energy Rev., 62, 767-792. https://doi.org/10.1016/j.rser.2016.04.050

Hussein, A., Walunj, A. and Kolsi, L. (2016): Applications of nanotechnology to enhance the performance of the direct absorption solar collectors, J. of Thermal Engg., 2, 1, 529-540.

Iordanou, G. (2009): Flat-plate solar collectors for water heating with improved heat transfer for application in climatic conditions of the mediterranean region, Doctoral thesis, Durham University.

Kalogirou, S.A. (2004): Solar thermal collectors and applications, Progress in Energy and Combustion Sci., 30, 231-295. https://doi.org/10.1016/j.pecs.2004.02.001

Karanth, K.V., Manjunath, M.S., Sharma, N.Y. (2011): Numerical simulation of a solar flat plate collector using discrete transfer radiation model (DTRM)-a CFD approach, Proc. of the World Congress on Engg., III, WCE 2011, London, U.K.

Karuppa, R.R.T., Pavan, P. and Rajeev, D.R. (2012): Experimental investigation of a new solar flat plate collector, Research J. of Engg. Sci., 1, 4, 1-8.

Kazeminejad, H. (2002): Numerical analysis of two dimensional parallel flow flat-plate solar collector, Renew. Energy, 26, 309-323. https://doi.org/10.1016/S0960-1481(01)00121-5

Khorasanizadeh, H., Nikfar, M., Amani, J. (2013): Entropy generation of $\mathrm{Cu}$-water nanofluid mixed convection in a cavity, Eur. J. Mech. B-Fluid, 37,143-152. https://doi.org/10.1016/j.euromechflu.2012.09.002

Kolsi, L., Hussein, A., Borjini, M., Mohammed, H. and Aïssia, H. Ben (2014): Computational analysis of threedimensional unsteady natural convection and entropy generation in a cubical enclosure filled with water-A12O3 nanofluid, Arabian J. for Sci. and Engg., 39, 7483-7493. https://doi.org/10.1007/s13369-014-1341-y

Lambert, A.A., Cuevas, S., del Ri’o, J.A. (2006): Enhanced heat transfer using oscillatory flows in solar collectors, Solar Energy, 80, 1296-1302. https://doi.org/10.1016/j.solener.2005.04.029

Li, D., Li, Z., Zheng, Y., Liu, C., Hussein, A. and Liu, X. (2016): Thermal performance of a PCM-filled doubleglazing unit with different thermophysical parameters of PCM, Solar Energy, 133, 207-220. https://doi.org/10.1016/j.solener.2016.03.039

Mahian, O., Kianifar, A., Kalogirou, S.A., Pop, I., Wongwises, S. (2013): A review of the applications of nanofluids in solar energy, Int. J. of Heat and Mass Trans., 57, 582-594. https://doi.org/10.1016/j.ijheatmasstransfer.2012.10.037

Mahian, O., Kianifar, A., Sahin, A.Z., Wongwises, S. (2014): Entropy generation during Al2O3/water nanofluid flow in a solar collector: Effects of tube roughness, nanoparticle size, and different thermophysical models, Int. J. of Heat and Mass Trans., 78, 64-75. https://doi.org/10.1016/j.ijheatmasstransfer.2014.06.051

Martín, R.H., Pinar, A.G., García, J.P. (2011): Experimental heat transfer research in enhanced flat-plate solar collectors, Solar Thermal Applications, World Renew. Energy Congress, 3844-3851.

Maxwell-Garnett, J.C. (1904): Colours in metal glasses and in metallic films, Philos. Trans. Roy. Soc. A 203, 385420. https://doi.org/10.1098/rsta.1904.0024

Nasrin, R. and Alim, M.A. (2014): Finite element simulation of forced convection in a flat plate solar collector: Influence of nanofluid with double nanoparticles, J. of Appl. Fluid Mech., 7, 3, 543-557.

Nasrin, R. and Alim, M.A. (2014): Semi-empirical relation for forced convective analysis through a solar collector, Solar Energy, 105, 455-467. https://doi.org/10.1016/j.solener.2014.03.035

Nasrin, R. and Alim, M.A. (2015): Thermal performance of nanofluid filled solar flat plate collector, Int. J. of Heat and Tech., 33, 2, 17-24. https://doi.org/10.18280/ijht.330203

Nasrin, R., Alim, M.A. and Chamkha, A.J. (2013): Effects of physical parameters on natural convection in a solar collector filled with nanofluid, Heat Trans.-Asian Res., 42, 1, 73-88.

Natarajan, E. \& Sathish, R. (2009): Role of nanofluids in solar water heater, Int. J. Adv. Manuf. Techno., 45, 5 pages, https://doi.org/10.1007/s00170-008-1876-8 
R. Nasrin, M.A. Alim and M. Hasanuzzaman/Journal of Naval Architecture and Marine Engineering, 13(2016) 135-150 Parvin, S., Nasrin, R. and Alim, M.A. (2014): Heat transfer and entropy generation through nanofluid filled direct absorption solar collector, Int. J. of Heat and Mass Trans., 71, 386-395. https://doi.org/10.1016/j.ijheatmasstransfer.2013.12.043

Parvin, S., Nasrin, R. and Alim, M.A. (2015): Heat transfer and collector efficiency through direct absorption solar collector with radiative heat flux effect, Num. Heat Trans. Part A- Application, 68, 1-21.

Polvongsri, S. and Kiatsiriroat, T. (2011): Enhancement of Flat-Plate Solar Collector Thermal Performance with Silver Nano-fluid, The 2nd TSME Int. Conf. on Mech. Engg., Krabi.

Reddy, J.N. and Gartling, D.K. (1994): The Finite Element Method in Heat Transfer and Fluid Dynamics, CRC Press, Inc., Boca Raton, Florida.

Saleh, A.M. (2012): Modeling of flat-plate solar collector operation in transient states, M. Sc. Engg. thesis, Purdue University, Fort Wayne, Indiana.

Sandhu, G. (2013): Experimental study of temperature field in flat-plate collector and heat transfer enhancement with the use of insert devices, M. of Engg. Sci. theseis, The School of Graduate and Postdoctoral Studies, The University of Western Ontario London, Ontario, Canada.

Schroeder, M. (2009): Utilizing the clean development mechanism for the deployment of renewable energies in China, Appl. Energ. 86, 2, 237-242. https://doi.org/10.1016/j.apenergy.2008.04.019

Shahi, M., Mahmoudi, AH., Raouf, AH. (2011): Entropy generation due to natural convection cooling of a nanofluid, Int. Commun. in Heat and Mass Transf., 38, 972-983. https://doi.org/10.1016/j.icheatmasstransfer.2011.04.008

Struckmann, F. (2008): Analysis of a flat-plate solar collector, Project Report 2008 MVK160 Heat and Mass Transport, Lund, Sweden.

Zambolin, E. (2011): Theoretical and experimental study of solar thermal collector systems and components, Ph. D. Thesis, Scuola di Dottorato di Ricerca in Ingegneria Industriale, Indirizzo Fisica Tecnica. 